\title{
Hacia una semiótica del arte Implicaciones del pensamiento peirceano en el estudio del arte contemporáneo*
}

\author{
Towards a semiotics of art \\ Implications of peircean thinking in \\ the study of contemporary art \\ Em direção à semiótica da arte \\ Implicações do pensamento peirceano no \\ estudo da arte contemporânea
}

Fecha de entrega: 20 de septiembre de 2014 Fecha de evaluación: 15 de noviembre de 2014 Fecha de aprobación: 15 de diciembre de 2014

In memoriam Charles Sanders Peirce

Pedro Agudelo Rendón ${ }^{* *}$

\section{Resumen}

La semiótica del arte es un campo de estudio que implica, más allá de los análisis formales, la revisión de aspectos y operaciones semióticas que solo son comprensibles desde un modelo tríadico. En este sentido, este texto examina las implicaciones del pensamiento de Charles

* Producto derivado del proyecto de investigación "Semiótica, educación y arte", realizado con apoyo del Centro de Investigaciones de Comunicaciones de la Facultad de Comunicaciones de la Universidad de Antioquia, Estrategia de Sostenibilidad 2014-2015.

* Miembro del Grupo de Estudios Literario GEL, Departamento de Lingüistica y Literatura, Facultad de Comunicaciones, Universidad de Antioquia UDEA, Calle 70 No. 52-21, Medellin, Colombia. 
Sanders Peirce en la semiótica del arte contemporáneo. Para eso, revisa sus principales aportes, presenta algunos de los estudios nucleares sobre la interpretación del arte desde la semiótica, y examina las nociones centrales de la teoría de Peirce que constituyen aportes originales para una semiótica del arte contemporáneo.

Palabras clave: arte cotemporáneo, objeto semiótico, semiosis, semiótica del arte, signo tríadico, símbolo.

\section{Abstract}

Semiotics of visual art is a field of study that involves, beyond the formal analysis, the revision of issues and semiotic operations that only are understandable from a triadic model. In this sense, this text examines the implications of Charles Sanders Peirce's ideas in the semiotics of contemporary art. For that, the text checks out some of his main contributions, it presents some of the nuclear studies on the interpretation of art from semiotics and examines the central notions of Peirce's theory that constitute original contributions to a semiotics of contemporary art.

Keywords: Contemporary art, semiotic object, semiotics, semiotics of art, triadic sign, symbol.

\section{Resumo}

A semiótica da arte é um campo de estudo que implica, além das análises formais, a revisão de aspectos e operações semióticas que só podem ser compreendidas desde um modelo triádico. Neste sentido, este artigo examina as implicações do pensamento de Charles Sanders Peirce na semiótica da arte contemporânea. Para isso, revisamos seus principais aportes, apresentamos alguns dos estudos nucleares sobre a interpretação da arte desde o ponto de vista da semiótica e examinamos as noções centrais da teoria de Peirce, a qual se constitui em aportes originais para uma semiótica da arte contemporânea.

Palavras-chave: Arte contemporânea, objeto semiótico, semiose, semiótica da arte, signo triádico, símbolo. 


\section{Preámbulo}

\subsection{Primeridad: la semiótica de Peirce}

Charles Sanders Peirce (1839-1914) es, sin lugar a dudas, uno de los pensadores más influyentes del siglo XX y de lo que va corrido del XXI. Prueba de ello son los diferentes eventos llevados a cabo en países como Estados Unidos, España, México, Argentina y Colombia, en los que se analizan sus teorías y se discuten o amplían sus postulados. Las Jornadas Peirce en Argentina son un ejemplo fehaciente, pues en este evento, desarrollado en Buenos Aires, se reúnen expertos en la teoría peirceana de distintas nacionalidades para exponer sus trabajos. Asimismo, son innumerables las publicaciones que comentan su obra o despliegan alguna de sus ideas. Autores de diferentes países se han dedicado al estudio pormenorizado del pensamiento peirceano, como es el caso del filósofo fránces Gerard Deledalle, quien sintetiza en su libro Leer a Peirce hoy (1996) las bases epistemológicas del trabajo del pensador estadounidense. Revistas como Anthropos. Huellas del conocimiento dedica uno de sus números a hacer una semblanza de Charles Sanders; mientras que, por su parte, el Grupo de Estudios Peirceanos (GEP), de la Universidad de Navarra, pone sus esfuerzos en la revaloración de sus aportes teóricos.

Y es que la influencia del pensador estadounidense es tan vasta, que incluso existen blogs de aficionados a la semiótica de Peirce, páginas de profesores que aplican sus postulados en sus clases, y artistas que bien pretenden aplicar los conceptos semióticos a sus obras o bien explican sus trabajos artísticos desde las categorías peirceanas, tal como lo hace la artista Gloria Torres (2001). Este último caso es un ejemplo de cómo las ideas peirceanas no solo han determinado áreas como la lógica, la matemática y la filosofía, sino también la estética, el análisis de obras de arte y la misma producción artística. Esto se debe, por un lado, a los temas que fueron objeto de su reflexión, como la lógica, la naturaleza de los sentimientos y el problema de las categorías; y, por otro, al modelo tricotómico que construyó y cuyos alcances son ilimitados.

El 'Cuadro de Peirce', o nonágono semiótico según los planteamientos realizados por algunos estudiosos del modelo peirceano (Guerri y otros, 2014), permite la comprensión de diferentes fenómenos sociales, y constituye un aporte significativo para entender la realidad artística en tanto postula un concepto de signo que supera una explicación diádica y sistémica de la obra artística, para hacer posible su comprensión 
desde procesos complejos que instauran el sentido a través de transformaciones semióticas de orden tríadico. Es cierto, como afirman Barrena y Nubiola (2010) que Peirce no era experto en arte y que muchas de sus opiniones no responden a una experticia en el tema, pero su modelo semiótico es tan consistente y potente que permite aprehender la realidad artística y estética de forma lógica y sensible. En este sentido, y tal como señalan los autores, para Peirce "el arte consiste precisamente en expresar algo y producir un efecto en quien contempla la obra de arte, en ser capaz de representar una cualidad de sentimiento haciéndola razonable, en actualizar esas posibilidades en qué consisten las cualidades en tanto primeridades" (Barrena y Nubiola, 2010: 22).

\subsection{Segundidad: aportes peirceanos para una semiótica aplicada}

Ahora bien, respecto de la interpretación de la obra artística, se puede afirmar que son cuatro los aspectos básicos que aporta el modelo de Peirce ${ }^{1}$. El primero de ellos es la originalidad en su definición de signo, y que constituye la base más importante de su sistema:

Un signo, o representamen, es algo que, para alguien, representa o se refiere a algo en algún aspecto o carácter. Se dirige a alguien, esto es, crea en la mente de esa persona un signo equivalente, o, tal vez, un signo aún más desarrollado (Peirce, 1974: 22).

Este concepto se inscribe, a su vez, en un marco más amplio: la concepción que el filósofo tiene de la actividad humana. Para él, la experiencia humana se organiza en tres niveles, a saber, Primeridad, Segundeidad y Terceridad. En términos generales, estos corresponden a las cualidades sentidas, a la experiencia del esfuerzo y a los signos.

El segundo aspecto determinante en el pensamiento peirceano es la clasificación que hace de las variedades de signos. Si en Ferdinand de Saussure la cifra 'dos' tiene un

1 Cuatro, por lo menos en términos de los propósitos generales que tenemos en el presente artículo, pues como se sabe, los aportes de Peirce en diferentes áreas son determinantes y vastos. Recordemos, por ejemplo, sus aportes en la lógica y, de modo indirecto, en la literatura, con la revaloración de los métodos de pensamiento deductivo e inductivo, y con el despliegue del método abductivo (véase Deducción, inducción e hipótesis, Peirce, 1970). 
papel protagónico por aludir a lo binario y, con ello, a todo un sistema que permite explicar diferentes fenómenos reales en tanto gramáticas o complejos culturales de orden sistémico; en Peirce lo es el 'tres', que hace posible el despliegue tricotómico para la comprensión de la realidad como variable e infinita, pero absolutamente cognoscible.

El tercer aspecto es la distinción de ícono, índice y símbolo, tres gradaciones de la Segundidad, esto es, de la referencia al objeto. Este último, en la relación tríadica de medio-objeto-interpretante, es entendido aquí como una cosa cualquiera que puede ser designada. En todo caso, por tratarse de un modelo abstracto, y en el sentido que lo plantea Peirce (1974: 37), se trata menos del objeto de la designación que de la referencia del signo al objeto ${ }^{2}$.

En cuarto lugar está la semiosis, o proceso sígnico, el cual está determinado por la terceridad, lo que permite comprender la estructuración de la experiencia humana por medio de signos. Los procesos generadores de signos tienen como punto de partida objetos materiales que son explicados por signos, pues el acto de conocimiento de una cosa, de acuerdo con Peirce, se constituye en signo de esta última. Dice el semiólogo: "predicar una cosa de otra es equivalente a establecer que la primera es un signo de la segunda" (Peirce, 5.321).

En el segundo capítulo serán ampliadas las implicaciones de estos aportes de Peirce para el arte contemporáneo. Antes de hacerlo, revisemos algunos de los trabajos de corte semiótico y peirceano que abordan el problema del arte y el análisis de la obra artística.

\subsection{Terceridad: los estudios semióticos sobre arte}

Desde sus inicios, la semiótica ha hecho aportes importantes en la comprensión de la obra de arte. Es cierto, también, que en muchos casos su jerga se convirtió en un problema de metalenguaje, de tal manera que muchos semiólogos terminaron hablando más de semiótica que de la obra en sí, con lo cual en vez de dar pautas de interpretación terminaron por oscurecer su sentido. Esto, si bien es coherente con el

2 Para ampliar la explicación del modelo tricotómico completo, remitimos al lector a los textos La ciencia de la semiótica de Peirce (1974); a "Charles Sanders Peirce, 1939/1914" de Zecchetto, Victorino (2002); y a Ser-signo-interpretante de Restrepo (1993). Aqui se presta atención especificamente en la referencia al objeto, es decir, a la Segundidad. 
momento histórico que se vivía -el paradigma lingüístico que instaura la metáfora del lenguaje según Fiz (1987)-, no es justificable, pues como dice Peirce (1974: 45), en la ciencia debe primar la claridad, y uno de los primeros deberes del investigador es "resistir enérgicamente a todo lo que sea un mandato arbitrario en materia científica y, más que nada, en materia de uso de términos y notaciones".

En el mundo académico se destacan, actualmente, diferentes trabajos, algunos con énfasis en los aspectos comunicativos y pragmáticos de la imagen artística; otros, más desde un enfoque visual, considerando diferentes aspectos del hecho perceptual. Este último es el caso del grupo $\mu$ (1993), que parte para sus análisis de la hipótesis según la cual la imagen visual es un sistema de significación con una organización interna autónoma (11). Por otra parte, y desde la perspectiva peirceana, el trabajo de Oliveras (2007) atiende a un estudio teórico y práctico, ya que plantea una serie de conceptos e instrumentos que constituyen herramientas para la interpretación de la obra de arte. Se destaca el hecho de que la autora aluda a artistas argentinos, lo que abre una posibilidad importante para el estudio de las artes latinoamericanas desde un enfoque semiótico.

Muchos estudios (incluido el de la autora argentina) como el de Furió (2002), se centran en la obra de arte pictórica. Esto permite reconocer, no solo que buena parte de la producción artística a lo largo de la historia la componen pinturas o artefactos gráficos, sino también que la pintura es un buen ejemplo de sistema semiótico y que, por tanto, facilita la aplicación de ciertos esquemas de análisis. No obstante, es necesario reconocer la limitación que imponen ciertos modelos en la comprensión de obras y medios artísticos tan disímiles como los que ofrece la contemporaneidad ${ }^{3}$. En la actualidad, la semiótica del arte debe reconocer las limitaciones impuestas por modelos que inicialmente sostuvieron sus interpretaciones exclusivamente sobre el hecho lingüístico y traslaparon el modelo del lenguaje al arte; es decir, una semiótica contemporánea del arte demanda la ampliación de sus horizontes conceptuales, y la extensión interpretativa de sus modelos de análisis.

En este punto se destaca el trabajo realizado por Salabert (2003: 253) ya que, sobre la base de la teoría peirceana, plantea un modelo de interpretación de las obras de

3 Un caso especifico es el modelo iconológico planteado por Erwin Panofsky, ya que se limita exclusivamente, en términos peirceanos, a la dimensión icónica. La limitación de este modelo radica, justamente, en que se centra solo en un grado de aprehensión sígnica en la obra de arte, cuando en muchos casos los artistas recurren a aspectos de orden matéricos. 
arte a lo largo de la historia sobre la base de tres planos semióticos: el eidético, que corresponde al formalismo y a las representaciones icónicas; el textural-gráfico, centrado en la indicialidad y gestualidad; y el de la recreación, referido al citacionismo y a los metalenguajes. Esto permite destacar la aplicación de categorías peirceanas tales como ícono, índice y símbolo, al tiempo que abre la posibilidad de desplegar el análisis a nuevos medios artísticos desde las artes del cuerpo, los audiovisuales y el landart, entre otros.

El trabajo de Salabert abre una perspectiva que, no obstante, todavía debe ampliarse más. $\mathrm{O}$ ¿qué ocurre con el primer y tercer correlato?, ¿qué sucede con el pensamiento cuando se ve enfrentado a una obra de arte?, ¿qué constituye primeridad de la Primeridad, segundidad de la Primeridad y terceridad de la Primeridad en una obra de arte?, ¿qué ocurre en la interacción que hay entre el espectador y la obra de arte contemporánea?

\section{Nociones centrales para una semiótica del arte de corte peirceano}

Estas discusiones están hoy vigentes, y es lo que permite volver sobre el pensamiento de Peirce para revisar algunas de sus categorías y nociones e inferir su operatividad en lo que sería hoy una semiótica del arte.

En este sentido, y tal como se indicó atrás, se pueden destacar, inicialmente, cuatro aportes determinantes del pensamiento peirceano. El primero de ellos, como se dijo, es su definición de signo, ya que sin este último no es posible un conocimiento sobre la obra de arte. Como dice Peirce (1998: 117):

No cabe la menor duda de que algo es un signo de todo lo que está asociado con él por semejanza, contigüidad o causalidad: no puede haber duda alguna de que todo signo evoca la cosa significada. Así, pues, la asociación de ideas consiste en esto, en que un juicio ocasiona otro juicio, del cual es el signo. Ahora bien, esto no es ni más ni menos que una inferencia.

El signo es un indicio evidente del que se hacen inferencias con respecto a algo latente, se trata más de una función que de algo material o físico. Un signo es una relación tríadica, razón por la cual en el modelo peirceano es preciso asumir la simultaneidad de sus miembros o referencias. Así, el medio es simultáneo con el objeto designado 
y con el interpretante significado. Cada una de estas referencias se fundamenta en una tricotomía, cuya función es la de establecer grados de referenciación y, en consecuencia, distintas maneras como es empleado el sistema sígnico en la semiosis.

Esto implica que considerar la obra de arte como signo no es solo determinar sus estructuras internas como sistema, sino también atender a las operaciones y funciones sígnicas. Si la semiótica general se pregunta, como dice Klinkenberg (2006: 35), por la configuración del sentido entre los humanos, una semiótica de las artes visuales abordaría los lenguajes poéticos construidos por la obra artística a partir de las funciones semióticas que le son inherentes y de las operaciones del artista y del espectador. Frente a las funciones semióticas, cabe destacar que la relación triádica es un medio $(\mathrm{M})$ en relación 'designante' con un objeto $(\mathrm{O})$, y en relación 'significante' con un interpretante (I). El proceso de designación implica que un signo requiere un referente, bien si es un objeto o una imagen que está en su lugar. Así, para comprender es necesario un dominio de lo real que sirve al signo y una remisión a través de la indicación. La significación, por su parte, comprende distintas operaciones por medio de las cuales se significa la realidad social y cultural mediatizada por los signos.

De esta manera, una obra como Untitled (Perfect Lovers) de Felix Gonzalez-Torres constituye un signo cuyo referente inmediato es la medición del tiempo, pero que en el contexto de una galería tiene muy poco que ver con esto, y está más cercano a una intención estética y política del artista. La obra, compuesta por dos relojes idénticos, puestos uno al lado del otro, empiezan marcando la misma hora, pero con el tiempo la batería de uno se acaba antes que la del otro. Se trata del inevitable camino hacia la entropía de las cosas, un homenaje que hace el artista a su compañero sentimental, Ross Lycock, quien fuera diagnosticado de SIDA. De modo que aquí la designación está determinada por el proceso de significación en el que opera el signo, es decir, dos objetos (los relojes) de uso cotidiano, constituyen una verdadera obra artística por cuanto funcionan como signo más allá de su función social -i.e.- ya que dicen algo (M) sobre algo (O) para alguien (I).

En segundo lugar está la clasificación de la variedad de signos. Esta variedad ${ }^{4}$ permite comprender diferentes dimensiones de la pieza artística. Así, por ejemplo, lo que le da a las obras de arte su carácter particular para ser consideradas sinsigno es la identificación de un signo par definido en cierto cruce de clases. La variedad de

4 Sobre la clasificación sígnica puede verse: Peirce (1974) y Zecchetto (2002). 
signos también permite determinar procesos propios de la interpretación artística a partir del signo, como la percepción o sensación cualisígnica.

En última instancia, el signo es una totalidad, un auténtico representamen del mundo, ya que contiene en sí mismo todos los entes posibles que pueden ser comprendidos a través de la Primeridad, la Segundidad y la Terceridad. De este modo, como referencia al medio, la obra es parte del mundo físico y material, como referencia al objeto es parte del mundo objetivo de los objetos o acontecimientos, y como referencia al interpretante es parte de las formas y relaciones del pensamiento del mundo espiritual. En este sentido, cada referencia del signo constituye una unidad tricotómica que hace posible la diversificación interpretativa de la obra, y le otorga características particulares en tanto objeto significativo.

Muchas de las obras de Christo y Jeanne-Claude, por ejemplo, constituyen verdaderos signos tríadicos, no solo porque están configurados como materialidad (segundidad de la Segundidad) y posibilidad perceptual (primeridad de la Segundidad) sino porque además producen un verdadero efecto sobre un intérprete. Una obra como Running fence o The umbrellas ${ }^{5}$ crean un verdadero signo interpretante que, a su vez, producirá otro. La estrategia del recubrimiento le da un carácter matérico e icónico diferenciador a las cosas, al tiempo que acoge una significación particular. The umbrellas, por ejemplo, es una instalación simultánea en Japón y Estados Unidos en la que los artistas siembran una serie de sombrillas de colores vívidos, azul en un país y amarillo en otro. El color, en esta obra en particular, es lo que permite su captación primera como cualisigno; su presencia, efímera, su condición sinsígnica; y el carácter convencional de las sombrillas, su naturaleza legisígnica, a tal punto que, después de instalados, los paraguas se convirtieron en atracción turística y muchas personas las usaron como sombrillas de veraneo.

El tercer aspecto es la subdivisión tricotómica de la Segundidad: ícono, índice y símbolo. El primero constituye el fundamento de cada representación del objeto. De modo que el ícono no está ligado a un objeto determinado, realmente existente, sino que establece una relación de semejanza:

5 Remitimos al lector a la imagen № 1. Las imágenes contenidas en este texto se utilizan al amparo de lo autorizado por el artículo 32 de la Ley 23 de 1982. 
Un ícono es un Representamen cuya Cualidad Representativa es una Primeridad de él en tanto Primero. Esto es, una cualidad que el ícono posee en tanto cosa lo vuelve apto para ser un Representamen. Así, cualquier cosa es apta para ser un Sustituto de otra cosa a la que es similar (Peirce, 1974: 46).

El ícono es interpretable en cualidades de sensaciones o apariencias, razón por la cual sirve para una buena visión de conjunto respecto de un dominio de difícil comprensión como una obra de arte abstracto. De hecho, puede afirmarse que la realidad no puede ser considerada únicamente como aquello que es verdadero gracias al conjunto de enunciados científicos, sino más bien aquello constituido en los procesos semiósicos en la medida en que la realidad se conforma como objeto de los signos. En este sentido, el ícono amplía nuestra conciencia del mundo a través de nuestra conciencia perceptiva.

Esto se ve claramente en varias de las obras de la artista Julia Montilla, cuyo interés por las 'apariciones religiosas', la ha llevado a configurar un proceso plástico en el que predomina la construcción de imágenes. Estas obras operan por medio del ícono y, en cierto sentido, amplían la visión de mundo a través de nuevas representaciones. Así, en su obra La construcción de una aparición, la artista recoge rasgos propios de la producción visual en el ámbito católico desde la existencia de tecnologías de la reproducción. La obra consiste en cuatro vitrinas que presentan la reconstrucción del fenómeno aparicionista de San Sebastián de Garabandal a partir de artículos de prensa, libros, archivos, revistas y álbumes. Lo que hace la artista es plantear una reflexión sobre la validación de las visiones a través de la recreación fotográfica, con el fin de amplificar el conocimiento sobre un tipo de saber popular que tiene su base fundamental en el ícono como una forma de mediación prelingüística.

El índice, por su parte, tiene una relación de conexión directa, causal o de nexo:

Cualquier cosa que atraiga la atención es un índice. Cualquier cosa que nos sobresalte es un índice, en cuanto marca la articulación entre dos partes de una experiencia. Así, un tremendo tronar indica que algo considerable ha sucedido, aunque no sepamos exactamente de qué se trata, pero puede ser probable que podamos conectarlo con otra experiencia (Peirce, 1974: 50).

Esta relación particular del índice con el objeto del signo hace del objeto un acontecimiento determinado, singular, individual y dependiente temporal y espacialmente. 
Esto es fundamental para el arte contemporáneo, dada la diversidad de medios plásticos, y no solo visuales, de los que se valen los artistas en la producción de sus trabajos.

Artistas como el colombiano Óscar Muñoz desarrollan una obra que demanda de la participación activa del espectador, al tiempo que, desde la imagen (icono) configura piezas del orden de la indexicalidad, es decir, obras en las que prima la materia y sus circunstancias. Margarita Malagón (2010) analiza la presencia indéxica en su obra, lo que permite comprender la función de la segundidad en una obra cuya base es la primeridad. A Muñoz le interesa la imagen, pero esta, en muchos casos, es el resultado de una producción matérica enfrentada a los avatares del tiempo. La imagen desaparece, como en su obra Re/trato, por gracia de su constitución material; o aparece, como en Aliento $0^{6}$, por la participación activa del espectador y su intervención física.

Estas concepciones del ícono y del índice es lo que lleva a Salabert (2003) a distinguir entre un tipo de arte eidético y otro de orden textural-grafico. Pero también permiten comprender que la obra de arte, entendida como una unidad sígnica, es una totalidad, una relación de tres elementos, como ya se ha dicho. Por eso es que el arte se entiende como una terceridad de carácter simbólico.

Un símbolo, según Peirce (1974: 30) "es un signo que se refiere al Objeto que denota en virtud de una ley, usualmente una asociación de ideas generales que operan de modo tal que son la causa de que el Símbolo se interprete como referido a dicho Objeto". Por eso, el símbolo abarca multitud de objetos, en tanto que se lo puede concebir como un conjunto de variables. Es decir que su interpretación depende del intérprete, quien selecciona un medio cualquiera de un repertorio para designar. Si bien es cierto que los símbolos cumplen una función determinante en todos los sistemas de signos de las ciencias, son también indispensables para la representación de objetos y acontecimientos artísticos.

Esto permite explicar aquellos casos en los que la semejanza o las relaciones indéxicas no cumplen un papel determinante porque la representación del singular no designa al referente, sino que la designación se da por vía simbólica. Puesto que todo arte se atribuye a sí mismo un carácter simbólico, las prácticas artísticas contemporáneas se expanden en términos de los medios que emplean y de las estrategias que ponen en funcionamiento. De ahí que la presencia de signos indexicálicos en la obra de arte

6 Véase imágenes 2 y 3 
implique que el objeto se disfuncionalice y adquiera otros rasgos de orden simbólico. Los objetos, en su estado natural cumplen funciones causales o meramente empíricas, como una barrera formada de árboles que impide o mitiga el paso del viento; o una piedra que, por azar, desvía el curso de un arroyo. Ahora bien, los humanos empleamos los objetos y les atribuimos significaciones. En este caso, hablamos de funciones agentivas, como la que tiene la piedra que, limpia y cubierta con barniz, sirve de pisa papel. Pero los humanos también producen objetos (a los que son inherentes las funciones agentivas) como una máquina de coser o un orinal. Pero cuando la máquina sufre una avería (o su dueño decide seguir sus intuiciones decorativas), y se la usa de mesa, cambia su función: se ha disfuncionalizado. Lo mismo ocurre con el orinal, como el empleado por Marcel Duchamp para su obra Fountain.

En otras palabras, se puede decir sobre este proceso, y en relación con a presencia del objeto en la producción de obras de arte, que:

cambia la función semiótica del objeto de la realidad, de la imagen que la «representa» y de la obra de arte entendida como signo; es decir, ya no se trata de un arte que es el analogon de la realidad como pretendía Barthes (1986), sino de un arte que presenta indicios, huellas, señales que aluden a los objetos, a los hechos concretos, a las acciones (Agudelo, 2014b: 93).

El arte contemporáneo, libre de las ataduras que la originalidad le imponía a los artistas modernos, abre posibilidades de alcances no solo icónicos, indexicálicos y simbólicos, sino también contextuales, meramente sensitivos o experimentales y experienciales. Una artista como Katharina Grosse no busca representar sino crear sensaciones a través de la experiencia pictórica, y otra como Helen Escobedo no pretende crear una ilusión óptica a través de objetos reciclados, sino instaurar un nuevo orden simbólico y sensible a través de la experiencia de ver. Lo mismo ocurre con el arte colombiano. José Alejandro Restrepo crea una visión de la realidad nacional a través de la imagen como objeto de consumo, pero también desde sus cualidades primeras (primeridad de la Primeridad), o bien desde su presencia y efecto inmediato (segundidad de la Primeridad).

En cuarto lugar está la semiosis, que consiste en todo proceso que se refiere a signos, se desarrolla o es conducido por ellos. El principio de la semiosis está marcado por el carácter triádico involucrado en el signo y, por ende, en cualquier respuesta cognoscitiva concitada por él. En este orden de ideas, la obra de arte se inscribe en un 
circuito de comprensión más amplio que define su sentido gracias a una estructura categorial, activando con ello una interacción dinámica que define nuevos rumbos en la formación de hábitos. En este sentido, la subjetividad se transmuta en intersubjetividad, y el análisis de la dimensión formal de la obra artística en una cadena interpretativa y significativa de los efectos producidos por la obra-signo.

Los fenómenos artísticos contemporáneos son irreductibles a relaciones diádicas, y se abren a procesos que van más allá de las ideas clásicas de belleza, por cuanto se conectan con formas de producción de conocimiento. Esto pone de relieve su carácter heurístico en la medida en que dichos fenómenos están soportados en el pensamiento, y no solo en las cualidades de la forma. La semiosis, como se sabe, es en sí misma heurística, puesto que cualquier proceso requiere la producción de alguna hipótesis o un proceso de abstracción. Lo producido ('lo nuevo' en el arte) es concebible en cuanto se integra a un proceso de interpretación y entra a formar parte de la conciencia como signo. En consecuencia, 'lo nuevo' no es atribuible al objeto como cosa, sino a la categoría de signo en su integración al proceso de semiosis. Esto lo logran los artistas gracias a diferentes operaciones sobre la materia y los objetos.

Una de las operaciones semióticas artísticas más recurrente en el arte contemporáneo es la de la disfuncionalización, procedimiento que implica el encadenamiento de una serie de signos a partir de acciones sobre los objetos de la realidad material. La disfuncionalización del objeto está, entonces, en el hecho particular de que una imagen (un ícono) o un objeto material (un índice) transmuten su sentido icónico o indexical en simbólico. Así, cuando un artista como Carlos Uribe exhibe una montaña de maíz, esta no solo constituye una representación de lo que es una montaña, dado el grado de semejanza con una de las eminencias topográficas colombianas, ni está construyendo un mero artificio indexical al conectar un objeto (el maíz) con la realidad de la que proviene (la tierra, la montaña); sino que está creando desde las dimensiones icónica e indexicálica de su obra, un verdadero signo simbólico: la montaña de maíz significa otra cosa, a tal punto que suscita otra serie de signos interpretantes y otra serie de afectaciones y acciones, como la ocurrida en 2014 cuando un artista en formación introdujo una gallina al Museo de Arte Moderno de Medellín, en donde estaba expuesta la pieza, para que interactuara (¿se comiera?) el maíz de la obra de Uribe. Esta acción (-reacción) constituye un verdadero proceso de semiosis, infinita si se tuviera toda la vida para saber qué pasa en el futuro con la montaña de maíz, con la gallina, con las afectaciones sígnicas que dejó esta acción en el artista en formación, 
con los comentarios que se han hecho, con los comentarios de los comentarios, en fin, con todo aquello que no es posible conocer pero que, gracias al poder inferencial que otorgan los signos, sí se puede pre-suponer.

Todo esto, en palabras de Fajardo (2012: 101), permite la reflexión sobre las posibilidades epistemológicas de la semiótica peirceana y su función en el abordaje cognitivo de la obra de arte contemporánea. Una exploración de este tipo no solo contribuye en el despliegue de los postulados de Peirce, sino también en una mejor y más acertada mirada del arte desde la teoría de los signos.

\section{Epílogo}

Los aportes de Peirce son variados y diversos. Se puede decir que el pensador estadounidense amplía el campo de la lógica a las dimensiones de la semiótica, y le da a esta última una fundamentación desde la filosofía fenomenológica, específicamente, desde la faneroscópica y la pragmática, de carácter icónico e indicial. Y si bien su acercamiento al arte no es tan contundente como sí lo fue su trabajo en otros campos de saber, la consistencia de su modelo semiótico permite desplegar los análisis para abrir otros horizontes a lo que sería una semiótica del arte contemporáneo.

La semiótica del arte contemporáneo implica la comprensión de complejos procesos estéticos, intelectuales e institucionales, pues el arte ya no se entiende como una representación de la belleza, sino como una forma de pensamiento que implica una dimensión artística y estética, así como unas maneras de entretejer campos conceptuales por medio de los cuales se cuestiona la realidad social.

El arte activa sentidos plurales gracias a relaciones intersubjetivas, como se puede derivar de la teoría tríadica del signo. Estos sentidos impelen el pensamiento y la emoción propios del arte como primeridad, como capacidad para captar cualidades y sentimientos para luego exhibirlas y contemplarlas por medio de signos. En este sentido, una de las tesis de Furió (2002) según la cual la interpretación de la obra de arte está determinada por aquello que sabemos más allá de lo que vemos, es un buen punto de partida en la observación de obras artísticas contemporáneas; pero no es el punto de llegada, pues por encima de la mera convencionalización está el poder del símbolo y la efectividad de la metáfora para revelar aquello que la realidad oculta en su aparente evidencia material. 
En consecuencia, la semiótica del arte tiene en el pensamiento de Peirce una serie de herramientas conceptuales que permiten afrontar y sortear las dificultades que ofrecen los modelos lingüísticos. De hecho, como dice Eco (2007: 4), “el arte contemporáneo que se plantea como reflexión metalingüística sobre sus propias modalidades, en realidad ha privilegiado, en cada ocasión, una de esas modalidades y ha apostado solo a ella".

En este sentido:

la semiótica del arte ha de comprenderse como un ámbito dialógico que hace posible la interacción no solo de los sujetos con los objetos de conocimiento, con los signos o los fenómenos socioculturales, sino también con el otro, con la obra de arte como un dispositivo que activa pensamiento a través de la metáfora (Agudelo, 2014a: 3).

Sea como sea, los estudios sobre el arte desde una perspectiva peirceana abren un horizonte de comprensión de la obra pero también de la realidad cultural, de los fenómenos sociales que determinan la producción artística y del papel determinante que tiene el espectador experto o no. Observar una pieza artística es un acontecimiento sensible, pues se trata, siguiendo a Peirce, de un encuentro con aquello primero que es o existe con independencia de alguna otra cosa. Desde el punto de vista de la crítica implica, como señala Eco (2007: 1), preguntarse por las relaciones entre la investigación semiótica, los estudios estéticos y sociológicos del arte, pues, al fin y al cabo, el arte no es arte con independencia de la sociedad. 


\section{ILUSTRACIONES}

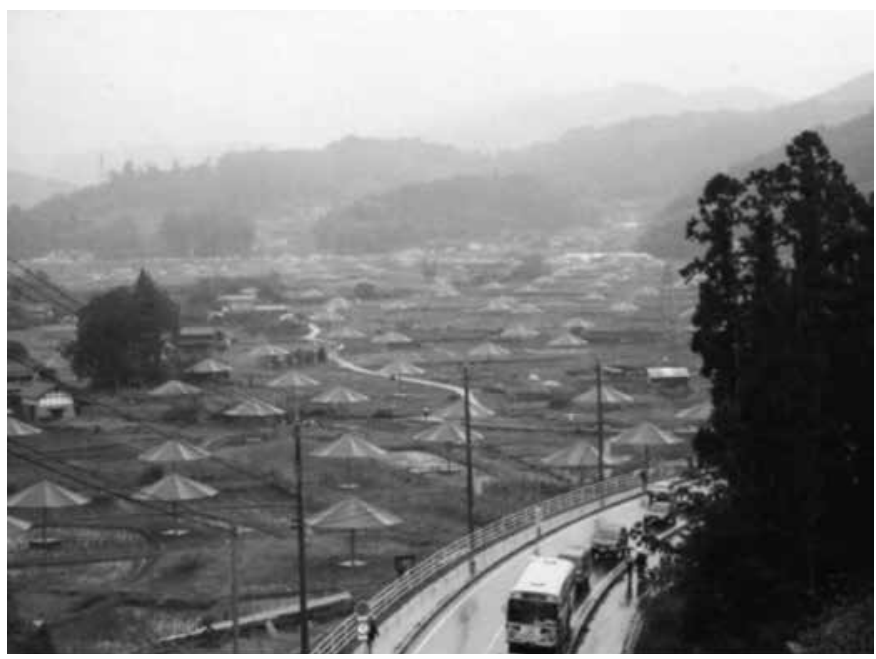

Figura 1.

Umbrella Project (Japan). Christo und Jeanne-Claude. Instalación. 1991. Imagen tomada de: http://commons.wikimedia.org/wiki/Christo

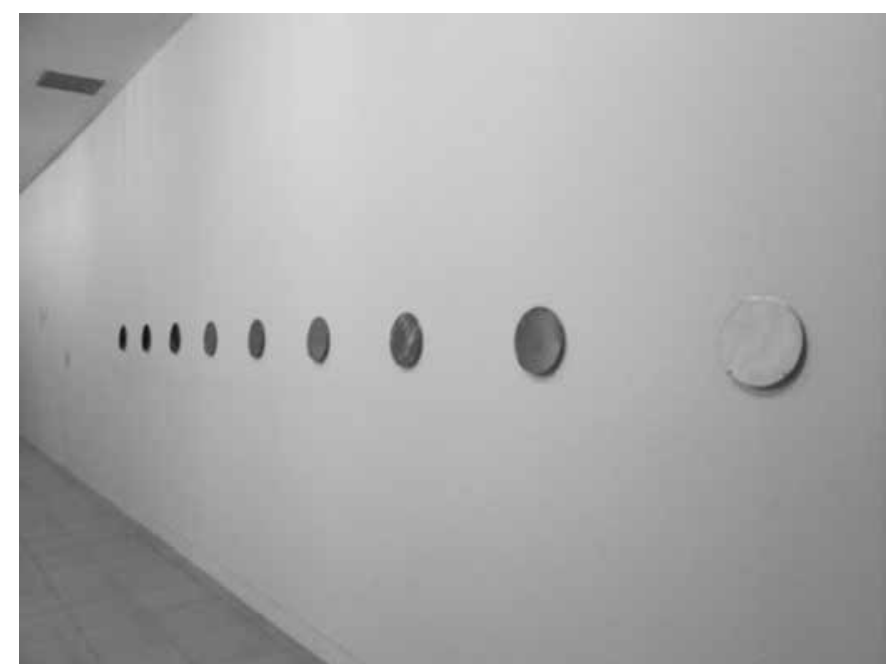

Figura 2. Plano general

Aliento. Óscar Muñoz. Serigrafía sobre espejos metálicos. 1995.

Fotografía: Pedro Agudelo 


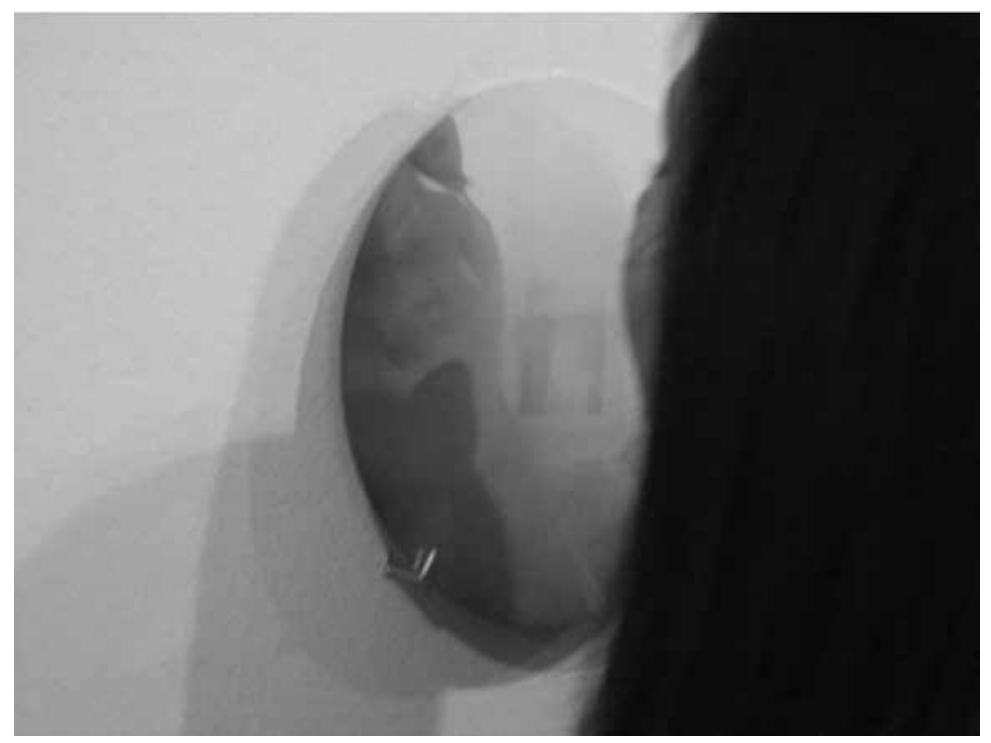

Figura 3. Detalle. Participación del público Aliento. Óscar Muñoz. Serigrafía sobre espejos metálicos. 1995.

Fotografía: Pedro Agudelo 


\section{Referencias}

Agudelo, P. (2014a). La experiencia artística más allá de la educación artística. Las posibilidades estéticas del pragmatismo y la semiótica peirceana. $V$ Congreso de Semiótica. Cali: Universidad Autónoma de Occidente.

. (2014b). Introducción a la semiótica del arte colombiano. Estudios de interpretación. Medellín: Fondo Editorial ITM.

Barrena, S. y Nubiola, J. (2010). Charles S. Peirce en Europa, 1870-71: Experiencia artística y estética. IV Jornadas "Peirce en Argentina". Buenos Aires: Academia de Ciencias de Buenos Aires, pp. 19-24.

Deledalle, G. (1996). Leer a Peirce hoy. Barcelona: Gedisa editorial.

Eco, U. (2007). Perspectivas de una semiótica de las artes visuales. Criterios, (25-28), 221-233.

Fajardo, R. (2012). Hacia un abordaje del objeto estético contemporáneo desde una perspectiva semiótica de raíz peirceana. IV Jornadas "Peirce en Argentina". Buenos Aires: Academia de Ciencias de Buenos Aires, pp. 101-110.

Furió, V. (2002). Ideas y formas en la representación pictórica. Barcelona: Ediciones de la Universidad de Barcelona.

Grupo $\mu$ (1993). Tratado del signo visual. Madrid: Cátedra.

Guerri, C. y otros (2014). Nonágono semiótico. Un modelo operativo para la investigación cualitativa. Buenos Aires: Eudeba, Ediciones UNL.

Klinkenberg, J. M. (2006). Manual de semiótica general. Bogotá: Universidad de Bogotá Jorge Tadeo Lozano.

Malagón, M. (2010). Arte como presencia indéxica: La obra de tres artistas colombianos en tiempos de violencia: Beatriz González, Óscar Muñoz y Doris Salcedo en la década de los noventa. Bogotá: Universidad de los Andes.

Marchán, S. (1987). La estética en la cultura moderna. Madrid: Alianza Editorial.

Oliveras, E. (2007). La metáfora en el arte. Retórica y filosofía de la imagen. Buenos Aires: Emecé editores. 
Peirce, C. S. (1998). El hombre un signo. Barcelona: Editorial Crítica. . (1974). La ciencia de la semiótica. Buenos Aires: Nueva edición. . (1958). Selected Writings. Values in a Universe of Change. (Wiener, P. ed.). Nueva York: Dover. . (1960). The collected papers. Ch. Hartshorne y P. Weiss (eds.) Cambrigde: Harvard University Press. . (1970). Deducción, inducción e hipótesis. Argentina: Aguilar.

Restrepo, M. (1993). Ser-signo-interpretante. Bogotá: Significantes de papel.

Salabert, P. (2003). Pintura anémica, cuerpo suculento. Barcelona: Laertes.

Torres, G. (2001). Análisis semiótico del discurso visual de un trabajo plástico. Revista del Centro de Ciencias del Lenguaje, (23), pp. 91-108.

Zecchetto, V. (2002). Charles Sanders Peirce, 1939-1914. Seis semiólogos en busca del lector: Saussure, Peirce, Barthes, Greimas, Eco, Verón. Argentina: La Crujia. pp. 37-70. 